02

\title{
Угловые зависимости спектров пропускания фотонно-кристаллических пленок на основе оксида алюминия
}

\author{
(C) П.П. Свербиль ${ }^{1}$, В.С. Горелик ${ }^{1,2}$, Dongxue $\mathrm{Bi}^{2}$, Guang Tao Fei ${ }^{3}$, Shao Hui Xu ${ }^{3}$, Xu Dong Gao ${ }^{3}$ \\ ${ }^{1}$ Физический институт им. П.Н. Лебедева РАН, \\ 119991 Москва, Россия \\ ${ }^{2}$ МГТУ им. Н.Э. Баумана, \\ 105005 Москва, Россия \\ ${ }^{3}$ Key Laboratory of Materials Physics and Anhui Key Laboratory of Nanomaterials and Nanotechnology, \\ Institute of Solid State Physics, Hefei Institutes of Physical Science, Chinese Academy of Sciences, \\ 230031 Hefei, China \\ e-mail: sverbil@sci.lebedev.ru
}

Поступила в Редакцию 04.06.2019 г.

В окончательной редакции 04.06.2019 г.

Принята к публикации 11.06.2019 г.

Исследованы угловые зависимости пропускания одномерного фотонного кристалла, созданного на основе пористого анодного оксида алюминия в диапазоне длин волн 320-1200 nm. Проанализирована возможность применения пористых одномерных фотонных кристаллов на основе оксида алюминия в качестве селективных узкополосных светофильтров и зеркал.

Ключевые слова: фотонный кристалл, стоп-зона, узкополосный фильтр, спектр пропускания.

DOI: $10.21883 /$ OS.2019.10.48355.176-19

\section{Введение}

В настоящее время весьма актуально создание новых типов зеркал и светофильтров с управляемыми оптическими свойствами. В связи с этим большой интерес представляет исследование фотонных кристаллов [1-4] - сред, диэлектрическая проницаемость которых изменяется в пространстве с периодом, допускающим брэгговскую дифракцию света. Примером такого рода структур являются одномерные фотонные кристаллы, построенные из чередующихся слоев с двумя различными показателями преломления $n_{1}$ и $n_{2}$. В спектре отражения таких кристаллов присутствуют области, в которых электромагнитное излучение отражается практически полностью. Такие области называются запрещенными зонами, или стоп-зонами. Спектральные положения стоп-зон зависят от периода решетки фотонного кристалла и показателей преломления его слоев.

Одним из видов фотонных кристаллов являются пористые структуры, содержащие поры размером в десятки нанометров [4-6]. Ранее исследовались оптические свойства пористых глобулярных фотонных кристаллов, построенных в виде гранецентрированной кубической решетки плотно упакованных шариков кремнезема $\left(\mathrm{SiO}_{2}\right)$ [7-10]. В последние годы был развит метод получения пористых одномерных фотонных кристаллов в результате электрохимического травления алюминия [11-13]. В результате были получены фотоннокристаллические пленки пористого анодного оксида алюминия, период решетки которых в зависимости от режима травления может изменяться в диапазоне
100-500 nm. В настоящей работе была поставлена задача исследования оптических свойств пористых одномерных фотонно-кристаллических пленок на основе оксида алюминия и анализа их угловых зависимостей с целью управления спектрами пропускания.

\section{Методика эксперимента и экспериментальные результаты}

В качестве образцов для исследования использовались тонкие многослойные пленки оксида алюминия, полученные с помощью электрохимического травления. Пленки состояли из чередующихся слоев с показателями преломления $n_{1}$ и $n_{2}$. Толщина пленок составляла около $20 \mu \mathrm{m}$.

Схема экспериментальной установки аналогична применявшейся в работах $[14,15]$. На рис. 1 приведен спектр пропускания исследуемой фотонно-кристаллической пленки в диапазоне длин волн электромагнитного излучения галогенной лампы 400-1200 nm. На рис. 2 приведен спектр пропускания исследуемой фотон но-кристал личес кой пленки в диапазоне длин волн электромагнитного излучения дейтериевой лампы $320-600 \mathrm{~nm}$.

Как видно из рис. 1 и 2, в спектрах пропускания электромагнитного излучения фотонно-кристаллической пленкой обнаруживаются резкие минимумы в области первой, второй и третьей стоп-зон, соответствующие длинам волн 1060, 530 и $350 \mathrm{~nm}$. При увеличении угла падения положения минимумов сдвигаются в коротковолновую область. Кроме того, наблюдается спад 


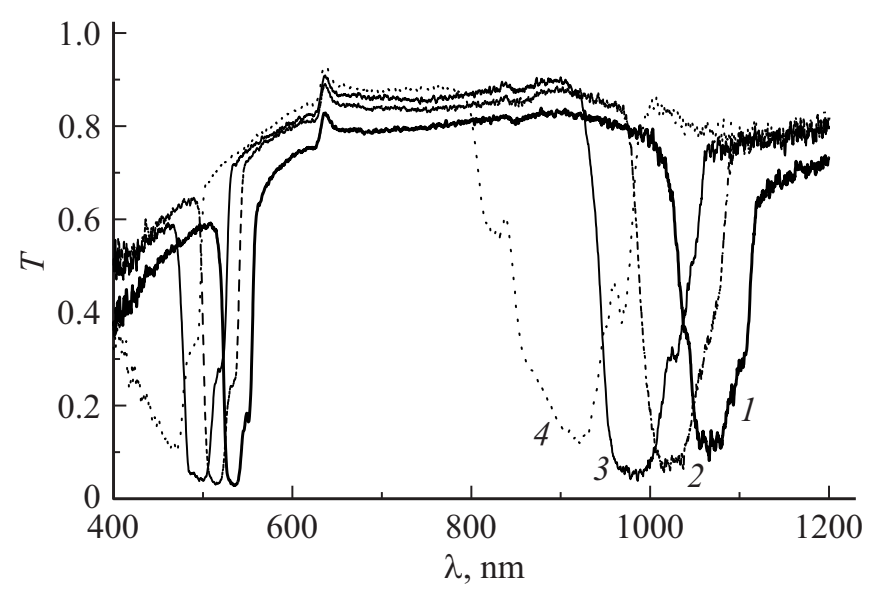

Pис. 1. Спектры пропускания излучения в диапазоне 400-1200 nm фотонно-кристаллической пленкой при различных углах падения света (кривые $1-0^{\circ}, 2-20^{\circ}, 3-30^{\circ}$, $\left.4-45^{\circ}\right)$.

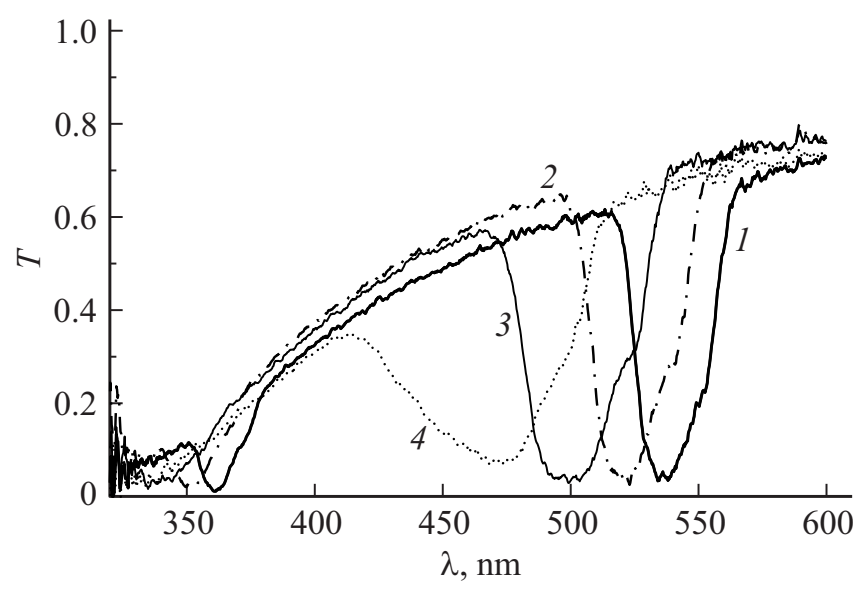

Рис. 2. Спектры пропускания излучения в диапазоне 320-600 nm фотонно-кристаллической пленкой при различных углах падения света (кривые $1-0^{\circ}, 2-20^{\circ}, 3-30^{\circ}$, $4-45^{\circ}$.

пропускания в коротковолновой части спектра, который может быть обусловлен поглощением в пленке и дифракцией на двумерной структуре пор в оксиде алюминия [15].

\section{Обсуждение результатов эксперимента}

Спектральные положения стоп-зон в зависимости от угла падения излучения на поверхность фотонно-кристаллической пленки задаются соотношением Вульфа-Брэгга [16,17]:

$$
m \lambda_{m}=2 d \sqrt{n_{\mathrm{ef}}^{2}-\sin ^{2} \theta} .
$$

Здесь $m=1,2,3$ - номера соответствующих стоп-зон; $\lambda_{m}$ - длина волны, соответствующая спектральному положению соответствующей стоп-зоны; $d=a_{1}+a_{2}$ период фотонно-кристаллической решетки; $a_{1}=a_{2}-$ толщины слоев; $\theta-$ угол падения излучения на поверхность фотонно-кристаллической пленки, $n_{\mathrm{ef}}$ - эффективный показатель преломления фотонного кристалла, вычисляемый по формуле

$$
n_{\mathrm{ef}}^{2}=\frac{a_{1}}{a_{1}+a_{2}} n_{1}^{2}+\frac{a_{2}}{a_{1}+a_{2}} n_{2}^{2},
$$

где $n_{1}, n_{2}-$ показатели преломления однородных слоев фотонно-кристаллической пленки.

Из соотношения (1) получаем выражение для периода фотонно-кристаллической решетки:

$$
d=\frac{m \lambda_{m}}{2 n_{\mathrm{ef}}\left(\lambda_{m}\right)}
$$

Показатели преломления каждого слоя пленки $n_{1}$ и $n_{2}$ связаны с пористостью слоя оксида алюминия выражениями

$$
n_{1}=\sqrt{\left(1-\delta_{1}\right) n_{3}^{2}+\delta_{1} n_{0}^{2}} ; \quad n_{2}=\sqrt{\left(1-\delta_{2}\right) n_{3}^{2}+\delta_{2} n_{0}^{2}} .
$$

Здесь $\delta_{1}$ и $\delta_{2}-$ пористости слоев 1 и $2, n_{3}$ и $n_{0}-$ показатели преломления монокристалла оксида алюминия и воздуха. Ширина $\Delta \lambda_{m}$ и спектральное положение $\lambda_{m}$ стоп-зоны с порядковым номером $m$ связаны с показателями преломления слоев соотношением [17]

$$
\frac{\Delta \lambda}{\lambda}=\frac{4}{\pi m} \frac{\left|n_{1}-n_{2}\right|}{n_{1}+n_{2}} .
$$

На основании спектров пропускания с учетом формул (1)-(5) были получены следующие значения параметров фотонно-кристаллической пленки: $n_{\mathrm{ef}}=1.37$, $n_{1}=1.3, n_{2}=1.44$.

На рис. 3 приведены зависимости положений центров первых трех стоп-зон фотонно-кристаллической пленки от угла падения света: сплошные линии - расчет по

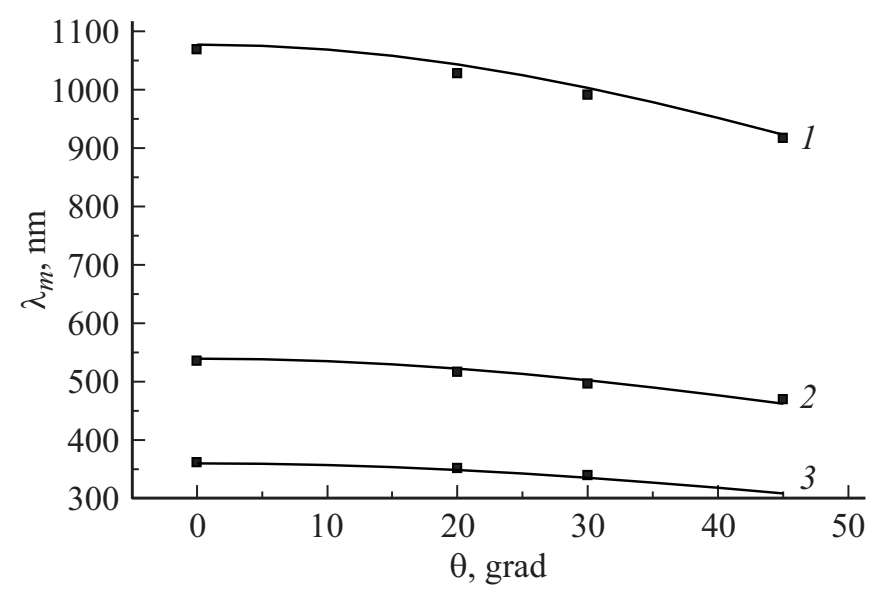

Рис. 3. Зависимости положений центров первых трех стоп-зон фотонно-кристаллической пленки от угла падения света $\left(\theta=0-45^{\circ}\right)$ : сплошные линии - расчет по формуле (1), точки - эксперимент. 
формуле (1), точки - эксперимент. Наилучшее совпадение расчета с экспериментом получено при значении периода фотонно-кристаллической пленки $d=390 \mathrm{~nm}$. В результате поворота исследуемого образца на $30^{\circ}$ по отношению к направлению луча света первая стоп-зона (в области длин волн $1100-1000 \mathrm{~nm}$ ) сдвигается на $80 \mathrm{~nm}$, а вторая (в области длин волн 550-500 nm) на $40 \mathrm{~nm}$ без существенного изменения формы спектра.

\section{Заключение}

В настоящей работе установлены спектральные положения первых трех стоп-зон фотонно-кристаллической пленки с периодом $390 \mathrm{~nm}$, синтезированной методом электрохимического травления алюминиевой пластины. На основе исследованного пористого фотонного кристалла анодного окисла алюминия могут быть созданы узкополосные фильтры, перспективные для анализа спектров комбинационного рассеяния или генерации оптических гармоник [15]. При этом точная подстройка полосы отражения фотонного кристалла достигается при его повороте на определенный угол в соответствии с формулой (1). Показана возможность использования обсуждаемых пористых пленок анодного окисла алюминия в различных оптических устройствах, основанных на использовании оптических свойств фотонных кристаллов.

\section{Финансирование работы}

Работа выполнена при частичной финансовой поддержке РФФИ (грант № 18-02-00181), China Scholarship Council и National Natural Science Foundation of China (grants № 51671183 and 51701207).

\section{Конфликт интересов}

Авторы заявляют, что у них нет конфликта интересов.

\section{Список литературы}

[1] Быков В.П. // ЖЭТФ. 1972. Т. 62. С. 505.

[2] Yablonovitch E. // Phys. Rev. Lett. 1987. V. 58. P. 2059.

[3] John S. // Phys. Rev. Lett. 1987. V. 58. P. 2486.

[4] Горелик В.С. // Квант. электрон. 2007. Т. 37. С. 409.

[5] Liu Yisen, Chang Yi, Ling Zhiyuan, Hu Xing, Li Yi. // Electrochem. Commun. 2011. V. 13. P. 1336.

[6] Svyakhovskiy S.E., Maydykovsky A.I., Murzina T.V. // J. Appl. Phys. 2012. V. 112. P. 013106.

[7] Ивченко Е.Л., Поддубный А.Н. // ФТТ. 2006. Т. 48(3). C. 540.

[8] Горелик В.С., Филатов В.В. // Краткие сообщения по физике ФИАН. 2010. № 2. С. 42.

[9] Горелик В.С., Филатов В.В. // Неорган. матер. 2012. Т. 48. № 4. C. 429.

[10] Горелик В.С., Лепнев Л.С., Литвинова А.О. // Неорган. матер. 2014. T. 50. С. 1086.

[11] Pavesi L. // Riv. Nuovo Cimento. 1997. V. 20. P. 1.
[12] Wang B., Fei G.T., Wang M., Kong M.G., Zhang L.D. // Nanotechnology. 2007. V. 18. P. 365601.

[13] Горелик В.С., Климонский С.О., Филатов В.В., Напольский К.С. // Опт. и спектр. 2016. Т. 120. № 4. С. 562.

[14] Горелик B.C., Яшин M.M., Dongxие Bi, Guang Tao Fei. // Опт. и спектр. 2018. Т. 124 (2). C. 171; Gorelik V.S., Yashin M.M., Bi Dongxue, Fei Guang Tao. // Opt. Spectrosc. 2018. V. 124. P. 167.

[15] Gorelik V.S., Sverbil P.P., Filatov V.V., Bi Dongxue, Fei Guang Tao, Xu Shao Hui. // Photonics and Nanostructures - Fundamentals and Applications. 2018. V. 32. P. 6.

[16] Born M., Wolf E. Principles of Optics. 4th. ed. Oxford: Pergamon Press, 1970; Борн М., Вольф Э. Основы оптики. М.: Наука, 1973. 713 c.

[17] Yariv A., Yeh P. Optical Waves in Crystals. Propagation and Control of Laser Radiation. N.Y.: Wiley, 1984. 589 p.; Ярив А., Юх П. Оптические волны в кристаллах. М.: Мир, 1987. $615 \mathrm{c}$. 